\title{
Use of C-C and C-N Molecular Emissions in Laser-Induced Breakdown Spectroscopy Data to Determine Diamond Provenance
}

\author{
Catherine E. McManus ${ }^{1}$, James Dowe ${ }^{2}$ and Nancy J. McMillan ${ }^{3}$ \\ 1. Materialytics, LLC, Killeen, Texas, USA. \\ 2. Analytical Data Services, Killeen, Texas, USA. \\ 3. Department of Geological Sciences, New Mexico State University, Las Cruces, New Mexico, USA.
}

Diamond provenance is a scientific problem with societal implications. Diamonds have played a significant role in human history as one of the major gemstones, in industrial applications, and as a method to convey great value in a small package. Recently, diamonds have been used as conflict minerals, used to finance illicit activity of rebel armies. The ability to accurately and quickly determine the country or mine of origin could eliminate conflict diamonds from the market, reduce terrorist funding, and save lives.

Techniques that have been applied to this problem include sample morphology, $\mathrm{N}$ concentration and aggregation state, and trace element concentrations. These techniques have not been able to determine provenance at a high level of accuracy[1]. Crystal morphology and $\mathrm{N}$ aggregation signatures are not unique to deposits. Trace elements in diamond reside in fluid or mineral inclusions; only $1 \%$ of diamonds contain inclusions [2], making trace element geochemistry an unreliable signal. The Kimberly Process, developed as an alternative to the scientific determination of provenance, certifies uncut diamonds by requiring them to be in tamper-resistant packaging with a Kimberly Process Certificate authorized by the country of origin. Several aspects of the Kimberly Process have been criticized, including the inability to certify cut stones and lack of monitoring by independent observers[3].

This study uses Laser-Induced Breakdown Spectroscopy (LIBS) analysis to accurately determine diamond provenance (overall 98.3\% accuracy). LIBS is an optical emission microanalysis technique in which laser ablation causes atoms to burn in a high-temperature plasma. Photons are emitted as the plasma cools and excited electrons relax. The spectrum of light $(200-1000 \mathrm{~nm})$ is collected by fiber optic, diffracted, and recorded on a CCD. LIBS spectra contain information on all elements in the periodic table, some isotopic ratios, and the electronic structure of the atoms in the material [4-6].

Bayesian statistics were applied to 2,310 spectra from 300 diamonds in this study (Table 1); spectra are presented in Figures 1 and 2. Thirty diamonds from each of eight natural locations were used, as were thirty diamonds from each of two manufacturers of synthetic diamonds. Each spectrum was compared to the mean spectrum of each group employing a Bayesian model based on the Euclidian distance between spectra. The probability of the spectrum belonging to each of the ten groups is calculated, and the spectrum is assigned to the group that has the highest probability. Table 1 lists the true positives, false positives, false negatives, and true negatives for each group. The success rate is the percent of the total number of spectra $(2,310)$ comprised by the sum of the true positives and the true negatives.

This study has high success rates (94.2\%-100\%). The key result of this study is that the molecular emission bands from $\mathrm{C}-\mathrm{C}$ and $\mathrm{C}-\mathrm{N}$ molecules control the multivariate statistical analysis rather than elemental lines. These bands are the broad humps between 380 and $500 \mathrm{~nm}$ (Fig. 1) [7]. One of the C-N emission bands, 380-390 nm, is shown in Fig. 2 [5]. The two diamond locations with no C-N emission band (Mir and Diavik) also lack N peaks (not shown). Serrano et al. [5] propose that small changes in C- 
$\mathrm{C}$ and $\mathrm{C}-\mathrm{N}$ emission bands are related to changes in the bonding structure of the atoms prior to ablation. Thus, this approach to determination of provenance is based on the diamond's carbon and nitrogen framework and has potential for accurately and rapidly determining provenance.

\section{References:}

[1] L Coney, TH Moila, and A Quadling, S. Af. Jour. Geol. 115 (2012) p. 33.

[2] T Stachel, and JW Harris, Ore Geol. Rev. 34 (2008) p. 5.

[3] L Gberie in "Movers and shakers: Social movements in Africa", ed. S Ellis and I van Kessel (Brill, Leiden) p. 63.

[4] DA Cremers and LJ Radziemski "Handbook of Laser-Induced Breakdown Spectroscopy", (John Wiley \& Sons, Chichester), 283 p.

[5] J Serrano, J Moros, and JJ Laserna, Anal. Chem. 87 (2015) p. 2794.

[6] RE Russo et al., Spectrochimica Acta Part B 66 (2011) p. 99.

[7] RWB Pearse, and AG Gaydon, "The Identification of Molecular Spectra", (Chapman and Hall, London, p. 407.

\begin{tabular}{lllllllll}
\hline Country & $\begin{array}{l}\text { Location/ } \\
\text { Manufacturer }\end{array}$ & $\begin{array}{l}\text { Deposit } \\
\text { Type }\end{array}$ & TP & FP & FN & TN & $\begin{array}{l}\text { Total } \\
\text { Spectra }\end{array}$ & $\begin{array}{l}\text { Accuracy } \\
(\%)\end{array}$ \\
\hline Australia & Argyle & lamproite & 236 & 0 & 1 & 2073 & 2310 & 99.96 \\
Australia & Ellendale & lamproite & 184 & 48 & 44 & 2031 & 2310 & 96.0 \\
Canada & Diavik & kimberlite & 230 & 4 & 7 & 2069 & 2310 & 99.5 \\
Canada & Ekati & kimberlite & 225 & 6 & 12 & 2067 & 2310 & 99.2 \\
Russia & Anabar & placer & 183 & 43 & 37 & 2047 & 2310 & 96.5 \\
Russia & Mir & kimberlite & 220 & 10 & 10 & 2070 & 2310 & 99.1 \\
Russia & Nizjni & $?$ & 176 & 56 & 77 & 2001 & 2310 & 94.2 \\
Sierra & Koidu & kimberlite & 197 & 34 & 14 & 2065 & 2310 & 97.9 \\
Leone & & & & & & & & \\
Synthetic & DNEA & ---- & 231 & 0 & 0 & 2079 & 2310 & 100 \\
Synthetic & Gemesis & ---- & 226 & 1 & 0 & 2083 & 2310 & 99.96
\end{tabular}

Table 1. Locations of the diamonds used in this study and results of multivariate analysis. $\mathrm{TP}=$ true positive; $\mathrm{FP}=$ false positive, $\mathrm{FN}=$ false negative $\mathrm{TN}=$ true negative .

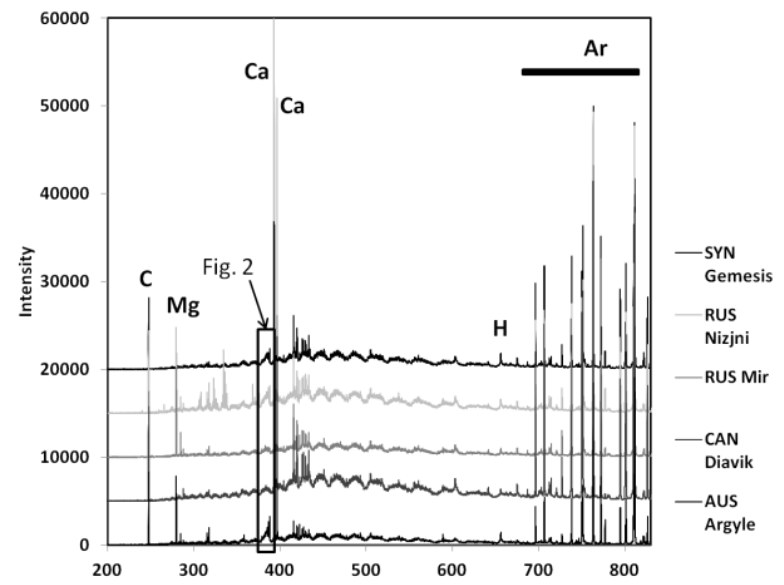

Figure 1. Spectra of representative samples; important emission lines and bands are labeled.

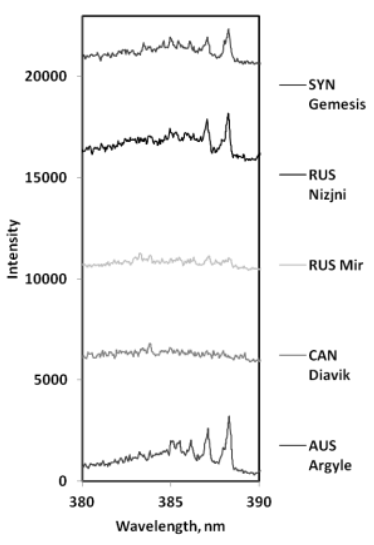

Figure 2. Spectra of C-N emission band at 380-390 nm. 